\title{
Penggunaan Metode Topsis dalam Sistem Pendukung Keputusan Pemilihan Karyawan Terbaik Pada SPBU 34.15306 Medang Karawaci
}

\author{
Rudianto $^{1}$
}

\begin{abstract}
Employees are the most important and core element in running the company's wheels so that it requires good employee performance who understands the company's vision and mission and can carry out their duties and responsibilities as well as possible. To improve performance, it is necessary to have an assessment atmosphere for all employees. SPBU 34. Medang Karawaci has so far conducted employee satisfaction assessments that have not used scientific methods so that the results are unfair and very subjective, causing disapproval of the results of the assessment. There needs to be a Decision Making Method (SPK) in assessing employee performance. The TOPSIS method is considered suitable to be used as a method in making decisions to choose the best employees from the concept, but problem solving including performance problems produced is objective and can be accepted by all parties.
\end{abstract}

Intisari- Karyawan merupakan unsur yang paling utama dan inti dalam berjalannya roda perusahaan sehingga membutuhkan kinerja karyawan yang baik yang paham visi dan misi perusahaan juga yang bisa menjalankan tugas dan tanggung jawabnya dengan sebaik mungkin. untuk meningkatkan kinerja karyawan perlu adanya mekanisme penilaian kinerja bagi seluruh karyawan. SPBU 34. Medang Karawaci selama ini melakukan penilaian karyawannya belum menggunakan metode apapun yang ilmiah sehingga dirasa hasilnya tidak adil dan sangat subyektif menimbulkan ketidak puasan terhadap hasil penilain tersebut. Perlu adanya metode Sistem Pengambilan Keputusan (SPK) dalam penilaian kinerja karyawannya. Metode TOPSIS dirasa cocok untuk dijadikan metode di dalam mengambil keputusan memilih karyawan terbaik karena konsepnya sederhana tetapi tahapan pemecahan masalahnya termasuk kompleks sehingga penilaian kinerja yang di hasilkan bersifat objektif dan dpat diterima semua pihak.

Kata Kunci-Kinerja Karyawan, Karyawan Terbaik, SPK, TOPSIS

\section{PENDAHULUAN}

Sumber Daya Manusia atau karyawan pada suatu perusahaan merupakan salah satu bagian penting dan vital. Berkembangnya suatu perusahaan sangat bergantung pada karyawan dan keterampilan para karyawan di dalamnya. Oleh karena itu harus di apresiasi dengan memperhatikan kesejahteraannya [1]. Agar kesejahteraan karyawan diperhatikan dan diapresiasi maka setiap karyawan dituntut

${ }^{1}$ Jurusan Teknik dan Informatika Universitas Bina Sarana Informatika, Jln. Kramat Raya No. 98 Jakarta Pusat 10450 INDONESIA (telp: 021-23231170; fax: 021-21236158; e-mail: rudianto.rdt@bsi.ac.id memiliki ketrampilan dan dapat memberikan kontribusi dan kinerja yang semakin meningkat maka karyawan perlu di evaluasi dan diberi penilaian kinerja secara berkala [2].

SPBU (Stasiun Pengisian Bahan Bakar Umum) tempat bagi masyarakat untuk mengisi bahan bakar kendaraan. Secara lebih jelas, SPBU memiliki fungsi sebagai tempat pembelian bahan bakar minyak secara eceran dan ritel untuk kendaraan bermotor roda dua, empat, atau lebih. SPBU berkode 34.15306 sering disebut SPBU Medang yang berada di jalan Raya Legok Karawaci Medang Pagedangan Kabupaten Tangerang adalah salah satu dari sekian banyak SPBU yang dimiliki PT Pertamina dengan jumlah karyawan sebanyak 19 karyawan.

Pada saat penulis melakukan penelitian di SPBU ini setiap bulannya melakukan evaluasi dan penilain untuk memilih karyawan terbaik untuk memacu semangat dan memotivasi karyawan dalam meningkatkan dedikasi dan kinerja . Pemilihan karyawan terbaik dilakukan secara periodik dalam rentan waktu perbulan akan tetapi belum optimal dalam pelaksanaan nya. SPBU Medang mendapat kendala dalam memutuskan karyawan yang di prioritaskan. kendala yang dihadapi adalah kepala SPBU Medang tidak menggunakan metode dalam memilih karyawan terbaik di SPBU Medang ini. Sehingga penilaian kinerja karyawan seringkali tidak adil dan bersifat subjektif. Untuk memecahkan masalah tersebut perlu dibuatkan sistem pendukung keputusan yang dapat membantu perusahaan terutama kepala SPBU dalam pengambilan keputusan untuk menentukan karyawan terbaik dengan metode TOPSIS. Didalam melakukan penilaian kinerja peneliti membuat kuisioner untuk mendapatkan nilai dari kriteria yang sudah di tentukan.

Metode TOPSIS ini merupakan yang sering dipergunakan oleh para peneliti di dalam konsep Sistem Penunjang Keputusan (SPK) karena konsepnya sederhana tetapi tahapan pemecahan masalahnya termasuk kompleks karena memilih alternatif jarak terdekat atau terpendek dari solusi ideal positif dan jarak terpanjang dari solusi idela negatif [3].

Maksud penelitian ini adalah menganalisis dan menerapkan salah satu metode dalam Sistem Penunjang Keputusan (SPK) untuk mengambil keputusan penilaian kinerja karyawan untuk hasil yang lebih ilmiah, efisien dan objektif. Metode ini dapat membantu para pihak pengambil keputusan untuk menentukan karyawan terbaik secara optimal dan proses penilaian kinerja karyawan dengan cepat tanpa membuang waktu lebih lama [3] Sedangkan tujuan dari penelitian ini adalah membantu para manajemen tingkat menengah dan atas dalam proses mencari karyawan terbaik secara efektif dan obyektif dengan menggunakan metode TOPSIS tidak lagi menilai karyawan 
secara sepihak karena tidak menggunakan metode SPK apapun [3].

\section{TINJAUAN PUSTAKA}

A. Sistem Pendukung Keputusan

Sistem pendukung keputusan adalah sistem interaktif yang menggunakan data dan model keputusan untuk memecahkan masalah semi terstruktur dan tidak terstruktur untuk membantu pengambilan keputusan. Dan lain halnya pengertian SPK biasanya didefinisikan sebagai sistem yang dapat memberikan pemecahan masalah dan keterampilan komunikasi untuk masalah semi-terstruktur [4]. Untuk itu diperlukan suatu sistem komputasi untuk memudahkan perusahaan dalam melakukan penilaian, sehingga penilaian lebih akurat, efektif dan efisien [5]. Pemecahan masalah atau problem solving tidak hanya mengacu pada pemecahan bidang/kesulitan masalah, tetapi juga mencakup menyelidiki peluang yang ada [6].

\section{B. Penilaian Kinerja Karyawan}

Menurut IPB penilaian kinerja Sejauh mana karyawan menyelesaikan tugas dan tanggung jawab yang diberikan kepada mereka oleh organisasi [7].

\section{Technique Order Performance by Similarity to Ideal} Solution (TOPSIS)

TOPSIS adalah cara untuk mendukung pengambilan keputusan yang optimal untuk memecahkan masalah keputusan dunia nyata. Memang, konsep ini sederhana, lugas, efisien secara komputasi, dan memungkinkan Anda untuk mengukur kinerja relatif dari alternatif keputusan dalam bentuk matematika sederhana [8].

Berikut adalah tahapan-tahapan dari metode TOPSIS sebagai berikut:

1. Menentukan matriks keputusan yang ternormalisasi

$$
r_{i j}=\frac{x_{i j}}{\sqrt{\sum_{i=1}^{m}} x_{i j}^{2}}
$$

2. Menghitung matriks keputusan yang ternormalisasi berbobot

$$
\begin{aligned}
& W=W_{1}, W_{2}, W_{3}, \ldots, W_{n} \\
& Y_{i j}=W_{j} \cdot r_{i j} \quad \ldots \ldots \ldots \ldots \ldots \ldots \ldots \ldots \ldots \ldots \ldots \ldots \ldots \ldots \ldots \ldots \ldots \ldots \ldots \ldots \ldots \ldots \\
& \text { Rumus }(1)
\end{aligned}
$$

3. Menghitung matriks solusi ideal positif dan matriks solusi ideal negative

$$
\begin{aligned}
& A^{+}=\left(Y_{1}^{+}, Y_{2}^{+}, \ldots, Y_{n}^{+}\right) \text {; } \\
& A^{-}=\left(Y_{1}^{-}, Y_{2}^{-}, \ldots, Y_{n}^{-}\right) \text {; }
\end{aligned}
$$

4. Menhitung jarak antara nilai setiap alternatif dengan matriks solusi ideal positif dan matriks solusi ideal negatif

$$
\begin{aligned}
& D_{i}^{+} \sqrt{\sum_{j=1}^{n}\left(Y_{i}^{+}-Y_{i j}\right)^{2} ;} \\
& D_{i}^{-}=\sqrt{\sum_{j=1}^{n}\left(Y_{i j}-Y_{i}^{-}\right)^{2}} ;
\end{aligned}
$$

5. Menghitung nilai preferensi untuk setiap alternatif

$$
V_{i}=\frac{D_{i}^{-}}{D_{i}^{-}+D_{i}^{+}}
$$

6. Nilai Vi yang lebih besar menunjukkan bahwa alternatif $\mathrm{Ai}$ lebih dipilih

\section{METODE PENELITIAN}

A. Tahapan Penelitian

Tahapan yang dilakukan dalam penelitian ini digambarkan dalam bagan sebagai berikut :

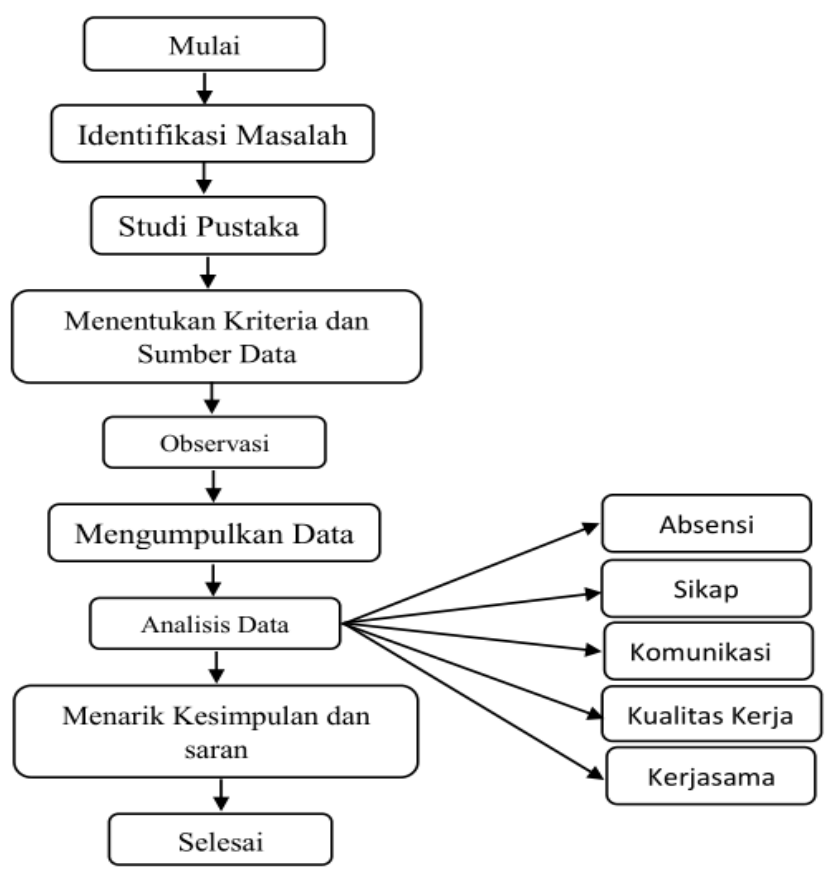

GAMBAR 1 FLOWCHART TAHAPAN PENELITIAN

B. Metode Pengumpulan Data

Metode pengumpulan data yang dilakukan peneliti dilakukan dengan 4 metode, yaitu :

1. Wawancara

Peneliti melakukan wawancara dengan Kepala SPBU Medang Karawaci Bapak Iyan Baihaqi dengan menanyakan jumlah karyawan, metode yang digunakan dalam pemilihan kinerja karyawan terbaik.

2. Observasi 
Penulis melakukan pengamatan secara langsung pada proses pemilihan karyawan terbaik di SPBU 34.15306 Medang Karawaci Jl. Raya Legok Karawaci Medang Pagedangan Kabupaten Tangerang.

3. Studi Pustaka

Mengumpulkan data-data primer dan data sekunder, data primer merupakan dokumen sumber dari tempat penelituan seperti dokumen daftar data karyawan sedangkan data sekunder merupaka data yang diperoleh dari luar tempat riset yang bersumber dari artike jurnal, prosiding, buku-buku.

4. Kuesioner

Menggunakan kuesioner untuk mengumpulkan data penilaian yang diisi olek kepala cabang per masing-masing karyawan untuk melakukan penilaian berdasarkan kriteria yang sudah ditentukan.

\section{Technique Order Performance by Similarity} to Ideal Solution (TOPSIS)

Tahapan-tahapan yang peneliti lakukan dalam peneltian menggunakan TOPSIS adalah sebagai berikut [8].

1. Menentukan matriks keputusan yang ternormalisasi

2. Menghitung matriks keputusan yang ternormalisasi berbobot

3. Menghitung matriks solusi ideal positif dan matriks solusi ideal negative

4. Menghitung jarak antara nilai setiap alternatif dengan matriks solusi ideal positif dan matriks solusi ideal negatif

5. Menghitung nilai preferensi untuk setiap alternatif

6. Nilai Vi yang lebih besar menunjukkan bahwa alternatif Ai lebih dipilih

\section{IV.HASIL DAN PEMBAHASAN}

A. Kriteria Penilaian Karyawan

Peneliti menggunakan beberapa kriteria dalam hal menentukan karyawan terbaik pada SPBU Medang Karawaci. Adapun beberapa kriteria sebagai berikut:

1. Presensi

Jumlah kehadiran dalam satu bulan berjalan.

TABEL 1 PENILAIAN KRITERIA ABSENSI

\begin{tabular}{clc}
\hline No & Absensi & Bobot \\
\hline 1 & $>25$ Hari kerja & 5 \\
\hline 2 & 22-24 Hari kerja & 4 \\
\hline 3 & $19-21$ Hari kerja & 3 \\
\hline 4 & $15-18$ Hari kerja & 2 \\
\hline 5 & 1-14 Hari kerja & 1 \\
\hline \multicolumn{2}{l}{ Sumber : Pengolahan Data Peneliti (2021) }
\end{tabular}

2. Sikap
Yang kedua kriteria sikap yang merupakan tindakan atau perbuatan karyawan yang dapat diamati dan dinilai melalui kusioner.

TABEL 2 PENILAIAN KRITERIA SIKAP

\begin{tabular}{ccc}
\hline No & Nilai Jawaban & Bobot \\
\hline 1 & $101-125$ & 5 \\
\hline 2 & $76-100$ & 4 \\
\hline 3 & $51-75$ & 3 \\
\hline 4 & $26-50$ & 2 \\
\hline 5 & $0-25$ & 1 \\
\hline \multicolumn{2}{l}{ Sumber : Pengolahan Data Peneliti (2021) }
\end{tabular}

3. Komunikasi

Proses penyampaian dan penerimaan suatu pekerjaannya

\section{TABEL 3 PENILAIAN KRITERIA KOMUNIKASI}

\begin{tabular}{ccc}
\hline No & Nilai Jawaban & Bobot \\
\hline 1 & $101-125$ & 5 \\
\hline 2 & $76-100$ & 4 \\
\hline 3 & $51-75$ & 3 \\
\hline 4 & $26-50$ & 2 \\
\hline 5 & $0-25$ & 1 \\
\hline \multicolumn{2}{l}{ Sumber : Pengolahan Data Peneliti (2021) }
\end{tabular}

4. Kualitas Kerja

Bagaimana karyawan melakukan pekerjaan dengan baik dan bertanggung jawab dalam melakukan pekerjaannya

TABEL 4 PENILAIAN KRITERIA KUALITAS KERJA

\begin{tabular}{ccc}
\hline No & Nilai Jawaban & Bobot \\
\hline 1 & $101-125$ & 5 \\
\hline 2 & $76-100$ & 4 \\
\hline 3 & $51-75$ & 3 \\
\hline 4 & $26-50$ & 2 \\
\hline 5 & $0-25$ & 1 \\
\hline Sumber : Pengolahan Data Peneliti (2021)
\end{tabular}

5. Kerjasama

Kemapuan mem backup pekerjaan karyawan yang tiba-tiba tidak masuk atau berhalangan datang saat jam kerja nya 
[VOL. X NO. 2 AGUSTUS 2021

JURNAL SISTEM

INFORMASI STMIK ANTAR

BANGSA

TABEL 5 PENILAIAN KRITERIA KERJA SAMA

\begin{tabular}{ccc}
\hline No & Nilai Jawaban & Bobot \\
\hline 1 & $101-125$ & 5 \\
\hline 2 & $76-100$ & 4 \\
\hline 3 & $51-75$ & 3 \\
\hline 4 & $26-50$ & 2 \\
\hline 5 & $0-25$ & 1 \\
\hline Sumber $:$ Pengoliti
\end{tabular}

Berikut adalah bobot benefit dari setiap kriteria yang diberlakukan.

TABEL 6 NILAI BOBOT KRITERIA

\begin{tabular}{lc}
\hline \multicolumn{1}{c}{ Kriteria } & Benefit \\
\hline Absensi (C1) & $10 \%$ \\
\hline Sikap (C2) & $15 \%$ \\
\hline Komunikasi (C3) & $20 \%$ \\
\hline Kualitas Kerja (C4) & $30 \%$ \\
\hline Kerja Sama (C5) & $25 \%$ \\
\hline
\end{tabular}

B. Data Karyawan

Berikut ini adalah data primer yang berisi data karyawan yang akan dinilai sebanyak 19 karyawan.

TABEL 7 DATA PENILAIAN KARYAWAN

\begin{tabular}{clccccc}
\hline \multirow{2}{*}{ No } & Nama & \multicolumn{5}{c}{ Penilaian } \\
\cline { 3 - 7 } & & C1 & C2 & C3 & C4 & C5 \\
\hline 1 & $\begin{array}{l}\text { Muhammad } \\
\text { Uyung Nurdin }\end{array}$ & 25 & 97 & 95 & 104 & 97 \\
\hline 2 & $\begin{array}{l}\text { Chaerul } \\
\text { Firmansyah }\end{array}$ & 25 & 89 & 96 & 106 & 96 \\
\hline 3 & $\begin{array}{l}\text { Sandi } \\
\text { Maulana Putra }\end{array}$ & 25 & 91 & 102 & 103 & 103 \\
\hline 4 & $\begin{array}{l}\text { Moch Arfan } \\
\text { Syafawi }\end{array}$ & 25 & 100 & 99 & 98 & 101 \\
\hline 5 & $\begin{array}{l}\text { Juliyanto } \\
\text { Prasetyo }\end{array}$ & 25 & 96 & 102 & 99 & 93 \\
\hline 6 & $\begin{array}{l}\text { Andre Putra } \\
\text { Wibowo }\end{array}$ & 24 & 96 & 97 & 98 & 89 \\
\hline 7 & $\begin{array}{l}\text { Budi Jaya } \\
\text { Purnama }\end{array}$ & 25 & 94 & 101 & 103 & 102 \\
\hline 8 & $\begin{array}{l}\text { Taufik } \\
\text { Mustofa }\end{array}$ & 24 & 102 & 102 & 103 & 103 \\
\hline 9 & Adi Purnomo & 25 & 85 & 100 & 105 & 97 \\
\hline 10 & Amin Trianto & 25 & 84 & 99 & 104 & 98 \\
\hline 11 & $\begin{array}{l}\text { Deden } \\
\text { Baihaki }\end{array}$ & 25 & 95 & 98 & 98 & 100 \\
\hline 12 & $\begin{array}{l}\text { Ahmad Ali } \\
\text { Mashuri }\end{array}$ & 25 & 101 & 101 & 99 & 101 \\
\hline 13 & Febi Aulia & 25 & 95 & 101 & 99 & 92 \\
\hline & & & & & &
\end{tabular}

\begin{tabular}{clccccc}
\hline 14 & $\begin{array}{l}\text { Taufan } \\
\text { Octavian } \\
\text { Utomo }\end{array}$ & 24 & 91 & 98 & 101 & 100 \\
\hline 15 & $\begin{array}{l}\text { Sehadib } \\
\text { Maulana }\end{array}$ & 25 & 91 & 93 & 101 & 100 \\
\hline 16 & $\begin{array}{l}\text { Nadia Saputri } \\
\text { Utami }\end{array}$ & 25 & 94 & 102 & 97 & 93 \\
\hline 17 & $\begin{array}{l}\text { Didik Beni } \\
\text { Santoso }\end{array}$ & 25 & 103 & 101 & 101 & 101 \\
\hline 18 & Idriyana & 25 & 90 & 94 & 97 & 82 \\
\hline 19 & $\begin{array}{l}\text { Andrian } \\
\text { Kusuma }\end{array}$ & 25 & 93 & 99 & 99 & 99 \\
\hline
\end{tabular}

Sumber : Pengolahan Data Peneliti (2021)

\section{Keterangan:}

C1: Absensi, C2: Sikap, C3:Komunikasi,

C4: Kualitas Kerja, C5: Kerjasama

C. Langkah-langkah Penyelesaian Metode TOPSIS

Adapun langkah-langkah penyelesaian masalah dengan metode TOPSIS yaitu sebagai berikut:

1. Menentukan matriks keputusan yang ternormalisasi

Dengan menggunakan rumus (1) maka hasil perhitungannya pada tabel 1 dibawah ini.

TABEL 8 MATRIKS KEPUTUSAN TERNORMALISASI

\begin{tabular}{clllll}
\hline No & C1 & C2 & C3 & C4 & C5 \\
\hline 1 & 0,236 & 0,220 & 0,206 & 0,252 & 0,211 \\
\hline 2 & 0,236 & 0,220 & 0,206 & 0,252 & 0,211 \\
\hline 3 & 0,236 & 0,220 & 0,258 & 0,252 & 0,264 \\
\hline 4 & 0,236 & 0,220 & 0,206 & 0,202 & 0,264 \\
\hline 5 & 0,236 & 0,220 & 0,258 & 0,202 & 0,211 \\
\hline 6 & 0,189 & 0,220 & 0,206 & 0,202 & 0,211 \\
\hline 7 & 0,236 & 0,220 & 0,258 & 0,252 & 0,264 \\
\hline 8 & 0,189 & 0,275 & 0,258 & 0,252 & 0,264 \\
\hline 9 & 0,236 & 0,220 & 0,206 & 0,252 & 0,211 \\
\hline 10 & 0,236 & 0,220 & 0,206 & 0,252 & 0,211 \\
\hline 11 & 0,236 & 0,220 & 0,206 & 0,202 & 0,211 \\
\hline 12 & 0,236 & 0,275 & 0,258 & 0,202 & 0,264 \\
\hline 13 & 0,236 & 0,220 & 0,258 & 0,202 & 0,211 \\
\hline 14 & 0,189 & 0,220 & 0,206 & 0,252 & 0,211 \\
\hline 15 & 0,236 & 0,220 & 0,206 & 0,252 & 0,211 \\
\hline 16 & 0,236 & 0,220 & 0,258 & 0,202 & 0,211 \\
\hline 17 & 0,236 & 0,275 & 0,258 & 0,252 & 0,264 \\
\hline 18 & 0,236 & 0,220 & 0,206 & 0,202 & 0,211 \\
\hline 19 & 0,236 & 0,220 & 0,206 & 0,202 & 0,211 \\
\hline Sumber : Pengolahan Data Peneliti $(2021)$ & &
\end{tabular}

2. Menghitung matriks keputusan yang ternormalisasi berbobot V

Menghitung proses ternormalisasi $\mathrm{V}$, dimana setiap alternatif diambil berdasarkan nilai dari kriteria nilai bobot dikali dengan kriteria hasil normalisasi (Rumus 2). 
TABEL 9 MATRIKS TERNORMALISASI TERBOBOT V

\begin{tabular}{clllll}
\hline No & C1 & C2 & C3 & C4 & C5 \\
\hline 1 & 0,024 & 0,033 & 0,041 & 0,076 & 0,053 \\
\hline 2 & 0,024 & 0,033 & 0,041 & 0,076 & 0,053 \\
\hline 3 & 0,024 & 0,033 & 0,052 & 0,076 & 0,066 \\
\hline 4 & 0,024 & 0,033 & 0,041 & 0,060 & 0,066 \\
\hline 5 & 0,024 & 0,033 & 0,052 & 0,060 & 0,053 \\
\hline 6 & 0,019 & 0,033 & 0,041 & 0,060 & 0,053 \\
\hline 7 & 0,024 & 0,033 & 0,052 & 0,076 & 0,066 \\
\hline 8 & 0,019 & 0,041 & 0,052 & 0,076 & 0,066 \\
\hline 9 & 0,024 & 0,033 & 0,041 & 0,076 & 0,053 \\
\hline 10 & 0,024 & 0,033 & 0,041 & 0,076 & 0,053 \\
\hline 11 & 0,024 & 0,033 & 0,041 & 0,060 & 0,053 \\
\hline 12 & 0,024 & 0,041 & 0,052 & 0,060 & 0,066 \\
\hline 13 & 0,024 & 0,033 & 0,052 & 0,060 & 0,053 \\
\hline 14 & 0,019 & 0,033 & 0,041 & 0,076 & 0,053 \\
\hline 15 & 0,024 & 0,033 & 0,041 & 0,076 & 0,053 \\
\hline 16 & 0,024 & 0,033 & 0,052 & 0,060 & 0,053 \\
\hline 17 & 0,024 & 0,041 & 0,052 & 0,076 & 0,066 \\
\hline 18 & 0,024 & 0,033 & 0,041 & 0,060 & 0,053 \\
\hline 19 & 0,024 & 0,033 & 0,041 & 0,060 & 0,053 \\
\hline
\end{tabular}

Sumber : Pengolahan Data Peneliti (2021)

3. Menghitung matriks solusi ideal positif dan matriks solusi ideal negative

Dengan Rumus (3) dan Rumus (4) Dari hasil perhitungan mencari solusi ideal positif A dan solusi ideal negatif A yang telah dilakukan maka dapat di lihat pada table di bawah:

TABEL 10 SOLUSI IDEAL POSITIF A DAN SOLUSI IDEAL NEGATIF A

\begin{tabular}{llllll} 
& C1 & C2 & C3 & C4 & C5 \\
\hline A+ & 0,024 & 0,041 & 0,052 & 0,076 & 0,066 \\
\hline A- & 0,019 & 0,033 & 0,041 & 0,060 & 0,053 \\
\hline
\end{tabular}

Sumber : Pengolahan Data Peneliti (2021)

4. Menghitung jarak antara nilai setiap alternatif dengan matriks solusi ideal positif dan matriks solusi ideal negatif

Perhitungan jarak antara alternatif A dengan solusi ideal positif dan negatif dengan menggunakan rumus (5) dan rumus (6), berikut hasil perhitungannya.

TABEL 11 HASIL PERHITUNGAN D POSITIF DAN D NEGATIF

\begin{tabular}{ccc}
\hline No & $\mathbf{D}^{+}$ & $\mathbf{D}^{-}$ \\
\hline 1 & 0,019 & 0,016 \\
\hline 2 & 0,019 & 0,016 \\
\hline 3 & 0,008 & 0,02 \\
\hline 4 & 0,020 & 0,014 \\
\hline 5 & 0,022 & 0,011 \\
\hline 6 & 0,024 & 0 \\
\hline 7 & 0,008 & 0,023 \\
\hline 8 & 0,005 & 0,024 \\
\hline 9 & 0,019 & 0,016 \\
\hline
\end{tabular}

\begin{tabular}{ccc}
\hline 10 & 0,019 & 0,016 \\
\hline 11 & 0,024 & 0,005 \\
\hline 12 & 0,015 & 0,019 \\
\hline 13 & 0,02 & 0,011 \\
\hline 14 & 0,019 & 0,015 \\
\hline 15 & 0,019 & 0,016 \\
\hline 16 & 0,022 & 0,011 \\
\hline 17 & 0 & 0,024 \\
\hline 18 & 0,024 & 0,005 \\
\hline 19 & 0,024 & 0,005 \\
\hline
\end{tabular}

5. Menghitung nilai preferensi untuk setiap alternatif Perhitungan Nilai Preferensi Untuk Hasil Setiap Alternatif menggunakan rumus (7), berikut hasil perhitungannya.

\section{TABEL 12 NILAI PREFERENSI SETIAP ALTERNATIF (V I )}

\begin{tabular}{clc}
\hline No & Nama Karyawan & Hasil (Vi) \\
\hline 1 & Muhammad Uyung Nurdin & 0,459 \\
\hline 2 & Chaerul Firmansyah & 0,459 \\
\hline 3 & Sandi Maulana Putra & 0,737 \\
\hline 4 & Moch Arfan Syafawi & 0,411 \\
\hline 5 & Juliyanto Prasetyo & 0,343 \\
\hline 6 & Andre Putra Wibowo & 0 \\
\hline 7 & Budi Jaya Purnama & 0,737 \\
\hline 8 & Taufik Mustofa & 0,836 \\
\hline 9 & Adi Purnomo & 0,459 \\
\hline 10 & Amin Trianto & 0,459 \\
\hline 11 & Deden Baihaki & 0,164 \\
\hline 12 & Ahmad Ali Mashuri & 0,560 \\
\hline 13 & Febi Aulia & 0,343 \\
\hline 14 & Taufan Octavian Utomo & 0,440 \\
\hline 15 & Sehadib Maulana & 0,459 \\
\hline 16 & Nadia Saputri Utami & 0,343 \\
\hline 17 & Didik Beni Santoso & 1 \\
\hline 18 & Idriyana & 0,164 \\
\hline 19 & Andrian Kusuma & 0,164 \\
\hline Sumber : Pengolahan Data Peneliti (2021) &
\end{tabular}

6. Nilai Vi yang lebih besar menunjukkan bahwa alternatif Ai lebih dipilih

Dari tabel 6 diatas diurutkan mulai dari paling besar ke paling kecil sehingga akan menghasilkan tabel 7.

TABEL 13 NILAI PREFERENSI DARI URUTAN TERBESAR (V I)

\begin{tabular}{clc}
\hline No & Nama aryawan & Hasil (Vi) \\
\hline 17 & Didik Beni Santoso & 1 \\
\hline 8 & Taufik Mustofa & 0,836 \\
\hline 3 & Sandi Maulana Putra & 0,737 \\
\hline 7 & Budi Jaya Purnama & 0,737 \\
\hline 12 & Ahmad Ali Mashuri & 0,560 \\
\hline 1 & Muhammad Uyung Nurdin & 0,459 \\
\hline 2 & Chaerul Firmansyah & 0,459 \\
\hline 9 & Adi Purnomo & 0,459 \\
\hline
\end{tabular}




\begin{tabular}{cll}
\hline 10 & Amin Trianto & 0,459 \\
\hline 15 & Sehadib Maulana & 0,459 \\
\hline 14 & Taufan Octavian Utomo & 0,440 \\
\hline 4 & Moch Arfan Syafawi & 0,411 \\
\hline 5 & Juliyanto Prasetyo & 0,343 \\
\hline 13 & Febi Aulia & 0,343 \\
\hline 16 & Nadia Saputri Utami & 0,343 \\
\hline 11 & Deden Baihaki & 0,164 \\
\hline 18 & Idriyana & 0,164 \\
\hline 19 & Andrian Kusuma & 0,164 \\
\hline 6 & Andre Putra Wibowo & 0 \\
\hline Sumber : Pengolahan Data Peneliti (2021) &
\end{tabular}

Pada tabel 7 dapat diputuskan bahwa yang menjadi karyawan terbaik adalah Didik Beni Santoso karena hasil (Vi) nya paling besar yaitu 1 .

\section{KESIMPULAN}

Metode TOPSI di dalam Sistem Penunjang Keputusan sangat efektif dalam menganalisis dan menghitung secara secara cepat dengan mempergunakan beberapa kriteria yang sudah ditentukan. Dari 19 karyawan yang dinilai kinerjanya dan menggunakan 5 kriteri yaitu kriteria presensi, sikap, komunikasi, kwalitas kerja dan kerjasama maka yang terpilih sebagai karyawan terbaik adalah Didik Beni Santoso karena hasil (Vi) nya paling besar yaitu 1.

\section{REFERENSI}

[1] W. Yusnaeni dan M. Marlina, "PEMERINGKATAN PENILAIAN KINERJA KARYAWAN MELALUI METODE AHP DAN VIKOR," PILAR Nusa Mandiri, vol. 15 No.2, pp. 204-209, 2019.

[2] R. N. Mawardi dan P. Handayani, "Sistem Pendukung Keputusan Karyawan Terbaik Menggunakan Metode TOPSIS Pada PT.Garuda Inti Karya," Reputasi: Jurnal Rekayasa Perangkat Lunak, vol. 2 No.1, pp. 14, 2021.

[3] A. B. Primahudi, F. A. Suciono dan A. A. Widodo, "SISTEM PENDUKUNG KEPUTUSAN UNTUK PEMILIHAN KARYAWAN DENGAN METODE SIMPLE ADDITIVE WEIGHTING DI PT.
HERBA PENAWAR ALWAHIDA INDONESIA,” JIMP - Jurnal Informatika Merdeka Pasuruan, vol. 2 No.1, pp. 57-80, 2016.

[4] H. Hertyana, "SISTEM PENDUKUNG KEPUTUSAN PENENTUAN KARYAWAN TERBAIK MENGGUNAKAN METODE TOPSIS," JITK, vol. 4 no. 1, pp. 43-48, Aug, 2018.

[5] Y. Siagian, "Seleksi Penerimaan Karyawan Baru Menggunakan Metode Topsis," Jurnal Mantik Penusa, vol. 2 no. 1, p. 65-70, 2018.

[6] M. S. Ma'arif dan L. Kartika, Manajemen Kinerja Sumber Daya Manusia, Bogor: PT Penerbit IPB Press, 2012.

[7] M. H. Hami, . H. Apriyani dan S. Sismadi, "METODE TOPSIS DALAM PENERAPAN KELUARGA HARAPAN (PKH) DI DESA KOTABATU KECAMATAN CIOMAS KABUPATEN BOGOR," Jurnal Mantik Penusa, vol. 3 No.1, pp. 77-81, 2019.

[8] R. Umar, A. Fadlil dan Y. Yuminah, "Sistem Pendukung Keputusan dengan Metode AHP untuk Penilaian Kompetensi Soft Skill Karyawan," khazanah Informatika, vol. 4 No.1, pp. 27-34, 2018.

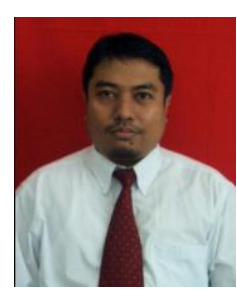

Rudianto, M.Kom lahir di Jakarta pada tahun 1977, lulus program strata satu (S1) Jurusan Manajemen Informatika Universitas Gunadarma pada tahun 2000 Tahun 2011 lulus program Pasca Sarjana Magister Ilmu Komputer STMIK Nusa Mandiri Jakarta. Saat ini aktif sebagai dosen di Universitas Bina Sarana Informatika dan STMIK Nusa Mandiri Jakarta, aktif menulis dibeberapa jurnal. 